With abnormal putrefaction, the stools become very foul and loose. Casein curds may be found as large as a small bean, tough, and insoluble in acetic acid and ether. It cannot be over-emphasized, however, that such curds are exceedingly rare, and that the small curds which are found in the stools are composed not of protein but of fat.

Of course, the "mixed" type of stools, with one or other factor predominating, is that most commonly encountered.

The stools of infants fed on whey or buttermilk mixtures are greyish brown in colour and alkaline in reaction. The stools of the infant fed on Nestlés milk are pale and look rather like broken-up curd. Dextrinized and malted foods impart a brown colour and an acid reaction to the fæces.

Bismuth salts, when given to adults, turn the stools black, owing to the formation of bismuth sulphide. In infants, this chemical change is exceptional.

In acute gastro-enteritis the stools become loose, green and very foul. It should be noted, however, that in some of the worst cases the dejecta may closely resemble serum, and be almost odourless.

\section{THE RELATIONSHIP BETWEEN CERTAIN DISEASES OF THE KIDNEY.}

a POST-gRaduate Lecture Delivered at THE METROPOLITAN HOSPITAL ON OCTOBER $31,1929$.

\section{$B$ By T. H. GOSTWYCK SHORE,} M.D., F.R.C.P.

MY object in this lecture is not merely to repeat to you all the descriptive material which can be read in any textbouk, but, so far as I can, to bring the accepted morbid changes into line with the clinical symptoms and biochemical findings, and so to simplify some of the difficulties surrounding a prope understanding of renal disease.

One of the chief of these difficulties hats been the accumulation of terms, some d $\overrightarrow{\text { est }}$ rived from morbid anatomy, some of puret clinical meaning, which have all at one time or another been in general use. Thus th kidney which we associate with arteriơ sclerosis has in its time had a dozen names or more, and " chronic interstitial nephritis $\overrightarrow{\bar{O}}$ includes several pathologically distinct con $\vec{\omega}$ ditions. I hope in the course of the lecture to clear a good deal of ground in this direction, and to put before you a ration nomenclature and classification in the light of present knowledge.

Let me remind you of the chief points upon which morbid anatomists rely when they consider the classification of ren disease from their point of view. The size and weight of the kidneys; the smoothne or roughness of the surface and the degref of such roughness; whether the capsule adherent to the surface of the organ readily removable; after dividing the kid the relative amounts of the cortex anct medulla, whether they are shrunken, scarred or blended, so that the line which ordinariß marks the one from the other is lost; the amount of intrapelvic fat; and the condition of the edges of the arteries which have been cut through. The colour of the kidney most misleading; a "small white kidney may be anything but white, and in ngy experience the kidney of acute nephritis $\ddot{\phi} s$ seldom red and dripping blood as some off the textbooks teach. A soft and friabse kidney suggests an acute condition, anged toughness or hardness points to long co tinued disease. In making a report upơn the histology the following four structures must be separately considered: the glom ruli, the tubuies, the arteries and the i terstitial tissue. A just assessment of the will generally lead to a reasonably accurabe opinion.

The study of morbid anatomy and hist logy lead as a first stage in classification $\mathbb{R}_{0}$ 
the recognition of three main groups: in the first the lesions are mainly to be found in the tubules and are of a degenerative nature; in the second the lesions affect all structures and are of an inflammatory nature ; in the third the lesions are dependent upon pre-existing arterial changes and are again degenerative in nature, but differ from the first group in that the final picture is one of extensive fibroid replacement. Within these three main groups are considerable variations, and to a certain extent the groups blend into one another. Absolutely clean-cut morbid conditions are almost as rare as absolutely typical clinical conditions.

\section{GROUP I.-NEPHROSIS.}

In pure cases of this kind the lesion is confined to the renal tubules. The glomeruli and interstitial tissues escape, so that the renal efficiency is not impaired and subsequent fibrosis of the organ is not found, and there are no changes in the cardiovascular system. The kidneys are sometimes enlarged, always smooth, and may be pale, though very often no change is to be found in the naked eye appearance. The tubular epithelium is swollen, and cloudy or foamy in paraffin sections. Frozen sections show a considerable amount of material in the tubular cells, and also in the lumen, which takes various stains which have specific affinity for fatty or "lipoid" - substances. Such lipoid substances can be found in the urine, and a characteristic feature of such cases is the constant high figure of the blood-cholesterol (normal I50 mg. per Ioo c.c.). The morbid appearances suggest that the kidney is the agent for the removal of this excessive lipoid, which causes tubular damage in its passage. The kidney is more sinned against than sinning.

In its milder forms this condition is seen in febrile albuminuria in such diseases as typhoid fever, pneumonia, diphtheria, the early days of scarlet fever, in tuberculosis and in many others. Exactly similar states can be produced experimentally in animals, and the knowledge gained from such experiments supports the clinical belief that if the underlying disease is removed the kidney recovers, and in the end suffers no permanent damage.

The milder cases present no clinical features beyond albuminuria, but in more severe ones there may be profound cedema though casts are uncommon and blood is, as a rule, absent. The blood-urea, the index of nitrogen retention and of severe glomerular involvement, is not raised in amount.

In a severe form this condition is seen in various kinds of poisoning, such as by phosphorus or mercury, and some of the best examples I have met have been caused by tri-nitro-toluol, by substances of the salvarsan group, and accompanying acute or subacute atrophy of the liver. In the case of some of these poisonous substances association is recognized with the circulating fat, in which they are soluble, as also is the fact that it is upon the liver and not upon the kidney that the brunt of the attack falls. A condition known as "myelin kidney" is occasionally found in which the accumula. tion of lipoid material in the tubules is visible to the naked eye; it is probable that these are cases in which the full development of lipoid nephrosis has existed until death, the causal factor remaining active till the end. The kidney of amyloid disease belongs to the group of nephrosis.

\section{GROUP II.-NEPHRITIS.}

The second or inflammatory group includes the cases to which the term "nephritis" should, strictly speaking, be contined. There is inflammation of the various structures which go to make up the kidney in contradistinction to a passive poisoning of its tubular epithelium without other structural change. In this group some permanent damage is produced in the 
kidney, and the symptoms and prognosis to a large extent depend upon its amount, and upon the degree to which repair can be effected and function restored.

The first subdivision of this group, glomerulo-tubal nephritis, is the one to which I should prefer to confine the term "nephritis," recognizing "embolic focal nephritis" and "pyelo-nephritis" as the other two separate entities included in the category of inflammation of the kidney.

In glomerulo-tubal nephritis the lesion is essentially a diffuse one involving, to a greater or less degree, glomeruli tubules and the interstitial tissue. In some mild cases in which there are practically no symptoms the lesion may be focal or localized to a comparatively small area, but such cases are difficult to diagnose, and their previous existence is inferred when death from some other cause has afforded opportunity for histological examination, or the more easily recognized diffuse condition has occurred by extension. That the process is a continuous and progressive one is shown by the fact that all stages of glomerular disease may be seen in the same section, indicating successive involvement of fresh glomeruli with the passage of time. In its initial stage this is the condition we have always recognized as "acute nephritis," but to arrive at a correct diagnosis the presence of blood and tube casts must be demonstrated, thus excluding the toxic kidney. As a rule the blood-pressure is not affected in the acute stage, and the size of the heart is normal. If the urinary findings point to acute nephritis and the blood-pressure is raised the condition is probably one of acute exacerbation of chronic nephritis, or an acute attack has supervened on a previously existing chronic condition. Some cases of acute nephritis appear to recover completely, though were it possible to make the examination some damaged tissue would almost certainly be revealed. The reserve of renal tissue is considerable, and renal insufficiency is not apparent nor the blood-urea raised until something in the region of two-thirds of the्ष total kidney tissue has been rendered hor de combat. It is possible for a person to be going about with a large amount of his kidney tissue functionless in complete ignorance of his condition, and for the fact to be quite unknown to his doctor unles occasion has arisen to test his urine.

Acute nephritis naturally passes on to the्ष subacute and chronic stages, and I prefe 5 these terms to the others in equally generait use as being more rational and more ex $\omega_{\sigma}^{\omega}$ planatory, though the nomenclature $\mathrm{ag}$ Aschoff, implying repair in the one stage an fibrosis in the other, are descriptive of the processes taking place. The term "secondar $\omega_{0}$ contracted kidney" implies a preceding acute stage in contradistinction to the "primary contracted kidney" of which then pathology is quite different.

It would be well now to recall that some cases of nephritis are accompanied by œdema and others are not. The œdematôn type have abundant albuminuria, diminished chloride output, normal blood-urea and cardio-vascular involvement-in fact re semble cases of nephrosis-but casts appea: in the urine. The others have scant albumin, normal urinary chlorides, a te $\vec{b}$ dency for the blood-urea to rise, and cardio 3 vascular symptoms which appear later. I $\overrightarrow{F_{8}}$ the first or "hydræmic" cases the urea-cori centration test is normal. In the second, of "azotæmic" cases, there is difficulty in the excretion of nitrogen compounds, and the urea concentration test shows that this subs stance can only be passed in suitable dilution These two types seem at first sight to be different diseases but all degrees of associa tion of the two occur, and the hydræmice type tends, if life continues, to pass on t $\beta$ azotæmic. Uræmia may supervene in eithơ case if severe renal failure occurs, and in the azotæmic type it is the natural termination of the disease. The similarity between the hydræmic cases and cases of nephrosis would suggest similar pathological lesions, and th is the case. Though nephritis is diffuse the 
tubules bear the brunt of the disease at this stage. The glomeruli are as yet sufficiently intact, and enough of them remain to prevent nitrogen retention. The cause of the tubular factor in the disease is still operative, nephrosis undoubtedly is present, and the blood-cholesterol is raised. As the hydræmic or nephrotic factor passes the azotæmic or sclerotic factor advances, and the result is a contracted, roughened kidney, with adherent capsule, reduced amount of cortex and medulla, increased intra-pelvic fat, thickened arteries and corresponding cardiac hypertrophy, in fact what we have hitherto known as a "small white kidney."

Nitrogen retention does not occur until a considerable proportion of the renal reserve has been drawn upon. Rose Bradford's experiments of thirty years ago demonstrated that three-quarters of the renal tissue could be removed before renal failure occurred. A vivid example of the great destruction that may occur is the congenital polycystic kidney, in which it is difficult to find any appreciable amount of functional tissue, the entire organ of both sides being apparently occupied by cysts of all sizes. We may then infer that an attack of acute nephritis may destroy a considerable amount of tissue without any alarming symptoms ensuing, very likely insufficient to prompt the patient to send for his doctor. How many cases of slight fever with pain in the back must pass as "influenza," especially during epidemics, the urine not having been tested. Such cases may, and probably do, advance slowly and insidiously through the subacute to the chronic stage, and only when the sclerosis of that stage has led to destruction of all the renal reserve do symptoms pointing to nephritis appear. Apparently the case is one of chronic nephritis which has always been chronic, and has not followed an acute attack. This is the type of case to which the term "Rose Bradford's kidney" has been applied.

Embolic focal nephritis is a condition which results from embolism in cases of septic (malignant, ulcerative, infective or subacute bacterial) endocarditis. The emboli may be few and of moderate size and lead to gross renal infarction, or they may be numerous and minute and then lead to no gross infarct but to this type of diffuse nephritis. The severity of the condition as an inflammatory one depends on the virulence of the causal organism and upon the amount of the renal tissue involved. Often the area of kidney tissue affected by a single embolic lodgment is very small, perhaps no more than a single glomerulus, but this repeated thousands of times by successive showers of emboli may eventually reduce the renal efficiency as much as any other glomerular infection. Emboli containing virulent organisms may cause further damage by the inflammation sprearing from the infected focus to the neighbouring tissue. Usually such cases die as do those afflicted with septic endocarditis, but sometimes the renal condition will outrun the cardiac ando renal failure results. The same embolic shower falls also on other organs, which do not as a rule suffer to the same extent as the kidney, because elsewhere the anastomoses of the terminal arteries are more efficient than in the kidney, and consequently minute emboli produce far less effect. The urine contains albumin and blood, though this may be in small amount and sometimes absent; the causal organism of the cardiac condition may be found in the urine when it contains blood. In advanced cases nitrogen retention may exist, but renal œdema seldom; there may be some casts, especially blood and leucocytic casts.

Before leaving the inflammatory group some mention should be made of pyelonephritis, which forms in renal disease the common meeting ground of physician and surgeon. I believe most if not all cases of so. called "pyelitis" should be considered to have some renal lesion. Pyelitıs is a common condition, especially in children and in relation to pregnancy, in the former being a not uncommon cause of unexplained 
fever; it often yields readily to treatment or appears to clear up without treatment, but I believe recurrences are common, particularly in cases from which the original cause has not been removed. The pathology of this condition is by no means proved and various views are taught. The majority of cases will be found to be associated with the passage of Bacillus coli in the urine; the minority pass other organisms. Many cases appear to be associated with disease of the appendix, but other chronic septic foci may be responsible. It seems probable that these organisms reach the kidney by way of the blood-stream, but the difficulty of isolating them from the blood is in marked contrast to the enormous numbers which are found in the urine, even if allowance is made for the great increase in numbers which undoubtedly takes place. after the urine has been formed and before it is voided from the bladder. This discrepancy could be explained by the supposition that some part of the kidney is actually infected by the organisms, a septic infarct being present. Recurrences and recrudescences are easily explained if this can be accepted, and in chronic cases which come to aulopsy the morbid appearances strongly point to such a pathological view. The kidney in the late stages is shrunken and coarsely scarred, irregular depressed areas marking the sites of previous inflammation and subsequent fibrosis. Fortunately the condition is apt to be unilateral, or at any rate one side is much more involved than the other, so that life may not be greatly shortened though health may long be impaired, with intercurrent acute attacks, or perhaps symptoms of stone or of hydronephrosis. Eventually the affected kidney may cease to function, and life will depend upon the health of the other, which is often hypertrophied. Death from uræmia is not common, but obviously depends upon the extent of the disease and the existence of complications. In the early stages the urine contains albumin, pus and swarms of micro-organisms, and is acid in reaction, later albumin may be scanty, pus absent and micro-organisms hardly apparent. The more acute cases may be of a severity to resemble some acute fever such as typhoid, the diagnosis in such cases resting on urinary examination. I believe that a considerable number of cases of this kind result from undiscovered or improperly treated pyelitis in early life. Pyelitis in pregnancy may end in the same way, but $\overrightarrow{0}$ being more readily diagnosed it is more efficiently treated, so that chronic pyelonephritis of this origin is not common.

The other type of gross renal infection is that which for long has been called the of "surgical kidney," more correctly " ascending nephritis." Here the primary sepsis o starts below and reaches the kidney by an ascending lymphatic path, such as has been demonstrated to exist and actually to be a path of infection of the kidney; this lies in the loose connective tissue which surrounds the ureter, connects with the retroperitonead lymphatics and with those from the colon The kidney when infected by this pate behaves in the same manner as has just been described, the cause of subsequent troubles depending on the implanted septic focus, and according to its severity a rapidly destructive lesion may soon kill the patient, or life may endure for a long time. This is a glimpse at the other side of the gradually narrowing chasm between Medicine and Surgery.

\section{Group III.-Vascular Degenerations.}

The last group of kidney diseases is that $\rightarrow$ in which the lesions result from disease of the arterial system, and includes two ज varieties in which arteriosclerosis or hyper- $N$ plastic sclerosis is the cause in one case, and atheroma or senile degeneration is the cause in the other. In either the kidneyco only participates in the general arterial disease, which to a greater or less degree affects the whole body. The organs mosto affected are those which depend for their 
ultimate blood supply on "terminal" or "end-arteries," that is by arteries which have little or no intercommunication, and so suffer from sudden or gradual vascular occlusion. Such organs are the kidney, the heart and the brain, any of which may become the central figure in arteriosclerosis. The disease of the hip-joint met in old persons, morbus coxæ senilis, and some cases of diabetes may be of the same nature.

The relationship of raised blood-pressure to renal disease is still a vexed question which I do not propuse to discuss here in detail. It is, however, in this group of renal disease that the highest pressures are found, and there can be little doubt that the elevation of pressure precedes the renal lesions, and death from cerebral hæmorrhage or cardiac failure may occur before any great degree of renal change can be detected. When the complete sequence of pathological events is studied they are found to be as follows. Hyperpiesia of some long duration is associated with thickening of arterioles, which gradually become occluded; those in the kidney, as this change overtakes them, can no longer maintain the nutrition of the glomeruli and tubes to which they are distributed, and these undergo ischæmic atrophy. The affected tissue is invaded by collections of small round cells and fibroblasts, fibrous tissue is laid down, and this by its contraction produces depressions on the surface of the organ; the areas of unaffected tissue which lie between the depressions produce the well known appearance which has given rise to the term "granular kidney."

This continuous pathological process can be divided on clinical grounds into three stages. In the first the high blood-pressure is the prominent sign and this is accompanied by cardiac hypertrophy, but there may be no symptoms whatever, and the condition is only found in a routine examination perhaps for life-insurance or some similar purpose. At this stage the kidney functions perfectly, and the urine will re- veal nothing. After a long interval there $\frac{a}{2}$ comes a time when gradual vascular blockage has produced an appreciable amount of $\stackrel{\varrho}{c}$ renal damage, and the kidney is unable to $\overrightarrow{\vec{c}}$ secrete all that is required of it except in $\frac{0}{0}$ more dilute solution than before. The듬 urinary output rises, and the familiar com- $\frac{\overline{\bar{S}}}{\vec{D}}$ plaint is made of nocturnal frequency $\stackrel{\mathbb{}}{\square}$ because the normal concentration of the night urine is no longer possible. There $\overrightarrow{0}$ are as yet no alterations in the blood- $\overrightarrow{\vec{H}}$ chemistry, and the whole picture has been $\stackrel{\omega}{\sigma}$ regarded as one of "compensated renalo failure." In the third stage the kidney can $\frac{3}{3}$. no longer perform its whole excretory on function even by passing urine in high dilu- $\infty$ tion, nitrogen retention gradually occurs, $\vec{\circ}$ tests reveal the failing function, and uræmia? sets in. Frequently the third stage is not 7 reached, for, as has been said, the kidney is을 not alone involved, and cardiac failure or cerebral hæmorrhage are as often the immediate cause of death as uræmia, perhas more often. When seen in the second stage the patient presents chiefly the features high blood-pressure with the associated cardiac hypertrophy; he may complain of headache, of gastro-intestinal symptoms, of $\stackrel{\mathbb{Q}}{\complement}$ polyuria or merely of a departure from his $\overrightarrow{\vec{O}}$ previous condition of "rude health." The $\frac{3}{3}$ urine is of low specific gravity, that passed by night and by day being more nearly the same as in health, there is little or no albumin and only occasional hyaline casts. Edema is absent. The blood-urea may be slightly raised as is the blood-cholesterol. Degenerative changes are found in theo fundus of the eye associated with thickened $\vec{D}$ arteries and engorged veins; flame-shaped을 hæmorrhages may be seen in the retina. N Blood is occasionally found in the urine in considerable amount for a short time; to this the name "renal epistaxis" has beeno applied, and it is presumably due to leakage from the kidney under the high bloodpressure.

By the "senile kidney" is meant simplyo the condition found in association with 
other phenomena of old age. Confusion has arisen because it often resembles the granular kidney in a general way, but there are quite definite differences. As age advances the requirements of the body decrease ; more or less atrophic cliange is found in all the organs, and in the kidney no more than the others. The point to remember is that with the decline of bodily and metabolic activity in a man, who has led an ordinarily healthy life, the gradual atrophy of his various organs goes on pari passu. The kidney is not required to perform so much work, and no longer has need of so much reserve, so the now useless excess undergoes atrophy. It is futile to fix any definite age as a criterion, for "a man is as old as his arteries," and his kidneys in this condition are of the same age. In contrast to the arteriosclerotic condition the blood-pressure is raised no more than is physiologically normal for his age, and and the heart, far from being hypertrophied, may even be smaller than usual, having shared in the general atrophy. Uræmic symptoms are absent, the blood-chemistry is unchanged, and the cause of death is normally cardiac failure, or some intercurrent disease.

I have put before you what I believe to be a rational classification of nephritis, and have endeavoured to justify it by reviewing the pathology and harmonizing it with the clinical aspect. It is not always possible, however, to assign a definite diagnosis to a particular case, for the results of clinical pathology are not sufficient clearly cut in all cases. I propose to discuss one or two diagnostic problems in the light of what has been already said.

First the patient with odema as the outstanding feature. Having excluded other non-renal causes of cedema the diagnosis in most cases seems clearly to be subacute nephritis, but the possibility of the trouble being of an entirely toxic nature must be remembered. Acute nephritis is generally sufficiently obvious, and the presence of blood and casts in the urine will practically clinch the diagnosis. Pure nephrosis is rare, but when its existence is more fully appreciated it will be more often found. If the water test and the urea concentration test are done no glomerular damage will be indicated. The appreciation of the fact that cases of nephrosis are expected to recover if the cause be removed should prompt a more thorough investigation; the treatment must be altered and the prognosis will be correspondingly different. According to Epstein, the appropriate treatment is a diet of high protein content to replace the large protein loss, and this can only be permissible if the glomeruli are known to be efficient. Epstein considers that the odema in these cases is directly the result of the protein loss, which alters the osmotic relations between the blood and the tissues. Whether this be true or not, such a diet does benefit nephrotic cases, but is not indicated in cases of true nephritis.

Another constantly recurring problem is the diagnosis in the case of raised blood-pressure. The two conditions in which this sign is marked are chronic nephritis and the arteriosclerotic kidney. Both conditions are commonly known as "chronic interstitial nephritis," and to this fact much of the confusion is doubtless due. The patient with chronic nephritis is usually pale, somewhat wasted and under 40 years of age, and he may or may not give a history of previous renal disease. The urine may contain a haze of albumin and a few granular or hyaline casts. The amounts of urine passed by day and by night are nearly equal, and the specific gravity almost the same. There is delay in passing the test feed of $30 \mathrm{oz}$. of water. There is some degree of anæmia, and retinitis of the exudative type. The level to which the blood-pressure is raised is not constant.

On the other hand, the patient whose kidney is of the arteriosclerotic type, and not yet in danger of failing, is well covered and robust; he declares that he has never had a day's illness, he is over to and may be over 
$5^{\circ}$, and he gives no history of previous renal trouble. The urine is of a similar character, but casts are less often found, and the amount of urine passed by night is less than the output by day. The response to the water test is fair. Retinitis is of the vascular type, with "silver wire" arteries crossing engorged veins, and glistening spots of degeneration which may be arranged in the star-shaped manner described in the textbooks. Retinal hæmorrhages may be found in both cases. The blood-pressure is on a higher level than in the chronic nephritic, and tends to maintain that level. Edema in either case results from cardiac failure and not from renal disease.

Even post mortem there may be difficulty in deciding between the "small white" and the "small red" kidney, which only shows how inadequate these terms are. A microscopic section should always clear the matter up, for whereas in chronic nephritis hardly a glomerulus escapes some inflammatory change, all possible stages being represented in some cases, in the arteriosclerotic kidney fibrotic and normal glomeruli are seen side by side, the healthy ones deriving their blood-supply from arterioles so far unoccluded.

Before concluding I wish to draw attention to one other troublesome kind of case. I refer to the patient who is first seen unconscious and is believed to be suffering from uræmia. The diagnosis is probably made on the grounds of high blood-pressure, a haze of albumin, and the absence of any other apparent cause of unconsciousness. If the patient is of the kind likely to have chronic nephritis this may be the trouble, but it is unlikely in the absence of some history of fits, twitching or other symptoms of uræmia. When, as not infrequently happens, the patient is not at all of that kind, I believe the treatment that used to be employed, bleeding and injection of saline, was as bad for him as could well be designed. Many of these are cases of myocardial weakness in which the blood-

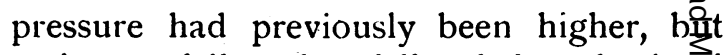

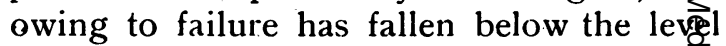
at which in the particular patient consciousness is maintained. The pressure needs 费 be raised to such a level that consciousness will return, and the amount of elevation necessary may be no more than 20 or $\bar{s} 5$ $\mathrm{mm}$., for these patients appear to live in narrow zone of pressure which is the optimum for the condition of their arter|ạl walls. They come to a stage when the zo $\overrightarrow{p e}$ in which they live is bounded as it were the devil and the deep sea, unconsciousnes if the pressure falls and cerebral hæmorrhage if it rises too much. My experience of treating these patients as uræmia was iobvariably that they clied. If they are left alone the same generally happens, but if the risk is taken of deliberately raising theृgr blood-pressures, by injection of digitalin a iad strychnine, they not infrequently regain coinsciousness and then can be treated simply as cases of heart failure, leaving hospita gin a few weeks. Though I appreciate that thexe is a risk in doing this I can see no har taking it as the chance of recovery af depletion or inactivity is very small. Actualigy in these cases there is no appreciable rise $\Phi$ the blood-urea, so that there is proof that $\overrightarrow{\overrightarrow{\underline{b}}} \mathrm{e}$ condition is not uræmia. There appeals also to be a type of case in which uncowsciousness is due to a further rise of pressise above the usual for the patient, the sy ptoms then more resembling those of stroke, and possibly are caused by arterial spasm; these are relieved by quite a small bleeding. In these cases the blood-pressuge is very high indeed, possibly exceedingry $300 \mathrm{~mm}$.

\section{CLASSIFICATION.}

\section{Group I- \\ Tubular degeneration $=$ Nephrosis}

Group II-

Nephritis.

(a) Glomerulo-tubal nephritis.

(I) Acute $\begin{cases}\text { Focal } & \text { Mild cases of acute neph } \\ \text { Diffuse } & \text { Ordinary acute nephritis. }\end{cases}$
Toxic or toxæmic kidney Myelin kidney in extreme caces 
( Large white kidney.

Chronic parenchymatous nephritis.

Secondary contracting kidney. Reparative stage (Aschoff).

Small white kidney.

(3) Chronic ... Chronic inters'itial nephritis.

Secondary contracted kidney.

Sclerotic stage (Aschoff).

(b) Embolic focal nephritis

The kidney of malignant endocarditis.

(c) Pyelo-nephritis.

(I) Acute

(2) Chronic

Septic nephritis.

Ascending nephritis.

" Surgical kidney."

\section{Group III-}

Vascular degenerations.

(a) Arteriosclerotic.

(Associated with arteriosclerosis and perhaps syphilis)

(b) Senile.

Small red kidney.

Gouty kidney.

Granular kidney.

Chronic interstitial nephritis.

Primary contracted kidney.

Renal fibrosis or cirrhosis.

(Associated with atheroma).

\section{E D I T O R I A L.}

We would like to bring to the notice of our readers a new scheme devised by The Fellowship of Medicine in order to widen its interests. The scheme, shortly, is to enrol medical societies throughout the country as associate members. Each society pays a fee of one guinea, and all members of these sccieties are entitled to join the Fellowship of Medicine at a reduced subscription. The Secretary of the Associate Society receives not only the Posi-Graduate JOURnal, but also all notices of courses, lectures, and so forth.

Members of the medical societies who have availed themselves of becoming individual members of The Fellowship of Medicine are entitled to the Journal and also to a 10 per cent. reduction of all fees for any courses that may be arranged through the Fellowship. Moreover, the Hon. Secretaries of The Fellowship of Medicine are only too anxious to render every assistance in their power and hope that they may be the means of meeting the demands for post-graduate teaching, which is increasing annually.

\section{POST-GRADUATE NEWS.}

Several Special Coursès on a variety of subjects are to be held during the month of February.

From February 4 to March I the Staff of the Bethlem Royal Hospital will hold a series of Lecture-Demonstrations on Tuesdays and Saturdays at 1 a.m. Fee $f_{\mathrm{I}}$ Is.

From February io to February 22 the Chelsea Hospital for Women will provide a Course in Gynæcology. Instruction is given mornings and/or afternoons, and the fee is $t_{5} 5^{\mathrm{s}}$.

A series of eight Clinical Demonstrations, extending over four weeks from February i I to March 6, will be given at the Hospital for Tropical Diseases on Tuesdays and Thursdays at 2 p.m. Fee $€ 22$ s.

For those interested in dermatology there is a month's course at St. John's Hospital for Diseases of the Skin, beginning February 17 and continuing until March $\mathrm{I} 5$. Instruction will be given daily, including Saturdays, in the Out-Patient Department, throughout the month, and there will also be a series of lectures given on Tuesdays and Thursdays at $5 \mathrm{p} . \mathrm{m}$. The fee for the course is $f \mathrm{I}$ Is. Practical pathological demonstrations can be arranged if desired. Fee $£ 44$ s.

An atternoon caurse, from Monday, February 24, to Friday, March 7, will be given at the Royal Eye Hospital, Southwark. Demonstrations on the Diagnosis and Treatment of Diseases of the Eye will be undertaken by Members of the Staff at 3 p.m. This Hospital is particularly fortunate in the number of clinical cases it receives, thus affording the Staff ample opportunity for demonstration purposes. Fee $£$ I Is.

Dr. Bernard Myers, the Director of the Children's Clinic, in association with several 